\title{
The Degree of Using Technology Tools by Adolescent and Its Effect on Them from Parents' Point of View
}

\author{
Rand B. Arabiyat ${ }^{1}$, Mo'en S. Al-nasraween ${ }^{1}$, Odeh A, Abusneineh ${ }^{1}$, Lina M. Maharmeh ${ }^{1}$, \& Rami I. Shogran ${ }^{1}$ \\ ${ }^{1}$ Faculty of Educational and Psychological Sciences, Amman Arab University, Amman \\ E-mail: Rand B. Arabiyat. Tel: 962-6479-1400. E-mail: rand@aau.edu.jo
}

Received: March 26, 2019

Accepted: April 2, $2019 \quad$ Online Published: April 30, 2019

doi:10.5539/ass.v15n5p66

URL: https://doi.org/10.5539/ass.v15n5p66

\begin{abstract}
This study aimed at investigating the degree of using technology tools by adolescent and its effect on them from their parent point of view, the study sample consisted from (370) parent whom were chosen by simple random way, a questionnaire was used consisting of four dimension. After assuring its reliability and validity it was conducted on the study sample, results showed that the degree of using technology tools by adolescent from their parent point of view was high, Results showed no statistically significant differences attributed to parent gender or scientific qualification in their estimation of using technology tools by adolescent. Finally the study recommended watching adolescent while using technology tools and determining time for using technology tools.
\end{abstract}

Keywords: technology tools, adolescent

\section{Introduction}

For many years, it was believed that what happens during infancy stage is a keystone for character development in the forthcoming years. Many effects left by early years' experience can never be ignored. However, there was a growing recognition that experience which was taken from other growth stages, especially adolescence; is equally important in affecting the forthcoming stages in a person's life.

Adolescence is a sensitive stage in a person's life; it represents a significant growth stage in body, brain and psyche; it is filled with psychological crisis and behavioral problems. Based on its importance, this stage is affected by earlier and the forthcoming stages. Despite the fact that an adolescent looks physically like an adult; an adolescent does recognize the consequences of actions and foresees things like adults; the reason refers to the immature brain of an adolescent (Smetana, 2006). In this stage, adolescents encounter many problems. Nevertheless, this is not limited to physical effect; it also includes different aspects of adolescent development. These problems can be classified as: physical, societal, emotional, cognitive and moral. The type of an individual adolescence depends on the ability to overcome and deal with problems, upbringing, health condition, stance of others, commitment to religion, societal restrains and ethics of society. The majority of adolescents go through several conflicts: The Inner Conflict; when an adolescent suffers from having many inner conflicts like living with and depending on family, memories of childhood, requirements of masculinity and femininity, excessive ambitions, obvious negligence for commitments, instincts and social traditions. In addition, the religious conflict between what has been learned of rituals, principles and postulates in childhood and the new critical thinking and philosophy of life. Moreover, the cultural conflict between the thoughts and opinions of the new generation and the old generation and the adolescent suffers from alienation and rebellion; also he complains from not being understood by parents (Corne \& Dahl, 2012).

That is why an adolescent attempts to have separate stances, principles and desires away from parents; as a way to confirm and approve individuality and differentiation. This implies rejecting authority of parents; an adolescent considers any authority and direction as an intolerable underestimation of mental abilities which were developed to be equal to the abilities of an adult in addition to, the critical thinking which allows an adolescent to scrutinize everything based on logic. Thus, this causes rebellious behaviors, arrogance, stubbornness, bigotry, aggressiveness, shyness and introversion; as too much spoiling and too much cruelty can make an adolescent feel like depending on others in solving problems. Nevertheless, the nature of this stage requires separating from family and being self-reliant. Therefore, the severity of conflicts increase and adolescents resort to disengagement from social world (Santrock, 2003). 
One of the major developments during adolescence are discovering life-long identity, constituting steps for the development of thoughts and opinions also setting life goals. These developments encourage an adolescent to have new interests in different fields. The most important ones in Arab societies are societal, vocational, religious and political relationships. This stage is characterized by the need for tests, experiments in these fields which will continue until adulthood it also takes different forms according to age. An adolescent looks for a personal identity by interacting with the surrounding people like relatives and friends, in addition to collecting experiences and ideas. The discovery of an identity is a right which can be transformed into reality by having a supportive environment for critical thinking and positive engagement and identity formation (Stickle, 2007). The spread of information technology and development of communication technology is considered as the biggest achievement of scientific revolution and modern technology as it made rapid changes in modern society; this technology has decreased distance especially the internet, gave a space for storing information, processing huge amounts of data. Therefore, this enabled individuals to receive information with an adequate speed and accuracy. Nowadays, an adolescent has the devices of modern century like mobile phones, computers, internet connection and other devices which started to affect an adolescent life directly carrying ideas which cannot be easily dealt with according to the nature of this stage (Rice \& Dolgin, 2005). Information society can be described as the flow of information that occurs using the networks of organizations and institutions, it represents a credible, refined and programmed series of interaction between financial spaces, unconnected and unoccupied by social activities in formal organizations.

\subsection{Impacts of Technological Devices on Individuals}

Information and communication technology is a double-edged phenomenon in terms of security, concern, entertainment and ingenuity. On one hand, it provided children and adolescents with new opportunities to dive into the internet, play electronic games and use chat rooms. On the other hand, parents are showing concerns towards losing the ability to observe children's accession to this technology and addiction to this world which left some negative impacts on children and adolescents (Wallenius, 2009), for instance; Alienation: the excessive use of this technology for fun like playing electronic games and browsing websites. In addition, spending long time in front of TV is linked to having weak societal skills and bad relationships with friends. Thus, a child or an adolescent feels alienated (Rice \& Dolgin, 2005).

Cultural integration is the most significant reason which will help on having cultural integration and harmonization is multimedia. Many thinkers are warning from the danger which these screens will cause of cultural integration that will threaten the national cultures by ignoring its features and privacy of its people. In addition, reluctance to read books and tendency to use electronic games, TV and computer resulted in increasing the number of illiterate people who hate to concentrate or make a small effort to obtain information. Therefore, these people prefer listening to media which requires less need to understand what it is broadcasted despite its accuracy or credibility.

Violence: Most of digital entertainment games which are popular in market include a violent content. This caused to assume that playing these games will make its players more aggressive. While analyzing the data of the study, it was found that these games increase violent emotions, perceptions and behaviors. Thus, it affects the societal behaviors. Consequently, playing violent games will lead to permanent changes in an individual's beliefs, attitudes and cognitive schemata which reside behind behavior.

Addiction: using technology and electronic games in specific; can be excessive if it was not organized. As computer games have a strong appeal, parents believe that their children spend a long time in playing these games and using internet. Thus, it will lead to addiction (Lee \& LaRose, 2007).

\subsection{Previous Studies}

In 2006, Michael Rich conducted a study about using computer and internet, it was made in The American Academy of Child on sample which consisted of 3500 children and adolescents their ages were between 12-18 years, they use the internet for more than 6 hours daily. Results have shown that there is a positive correlation between the long periods of using computer and internet and some of psychological disorders like violence, fear, depression and sleep disorders (Al-Ghamedi, 2007).

In 2004, Sonia Livingstone's study which was conducted on a sample that consisted of 200 children has shown that $(\% 20)$ of children use internet in their bedrooms, (\%79) of them use internet without any supervision. Moreover, results have shown that only (\%21) of children use the internet, $(\% 57)$ of adolescents have seen pornographic websites. Despite the fact that they surfed these websites by coincidence, the study has shown that (\%16) of parents believe that their children have surfed pornographic websites; this shows that these parents are not sufficiently aware of what their face in the internet of contractions and problems. 
In 2009, Laeri's study aimed to know the effect of psychological and social problems accompanying computer user in internet café in Kuwait, it consisted of 400 students. Results have shown that as a result of using internet in Cafe at the expense of their families for a long time, it caused different societal and psychological diseases and increased societal and family problems.

In 2003, Harvey Skinnner's study entitled by "How Adolescence use internet". It consisted of 210 individuals, males and females, in the United States of America. They were chosen to reflect variability in age, gender, origin and culture. Results have shown that (\%89) of adolescents use the internet to communicate with their friends, $(\% 85)$ for societal interests, $(\% 67)$ for medical information, (\%63) for body and nutrition, $(\% 59)$ for violence and body safety and $(\% 56)$ for sexual health.

In 2009, Rabee's study aimed to identify the extent of using internet in rural Egyptian society, the averages of usage between youth. Moreover, identify the most crucial psychological and societal effects of using internet and the extent of being influenced by these effects. In addition, identifying the relationship between the Demographic features of internet users, the level exposed to psychological and societal effects which will contribute to identify the way to use this modern technology positively. The study was at Monufia Governorate. The sample which consisted of 120 young students of Monufia University; their ages were 19-21. 60 of them were males and the rest were females who actually use the internet. The study population was divided into categories according to demographic variables like the economic and societal levels, gender, age and faculty of each student. The study results' results were entertainment websites came in the first place in terms of being favored by sample, whereas the educational and political websites came in the fourth and fifth place. Thus, most of youth use websites for useless purposes, what is dangerous here is that their ages are less than thirty years. Thus, this will lead to negative addiction on internet. This kind of addiction is related to low social interaction, lack of psychological existence. Thus, it increases depression, alienation and nervousness. Internet addiction separates an individual from the self and reality. Furthermore, the study emphasized that there is negligence in the role of media in raising awareness of individuals about how to use internet.

Another study made by Al-Kahki (2009), aimed to recognize the impact of psychological and societal effects of using internet by the students of Sharja University. In addition, it aimed to identify the sample's opinions, impressions from using internet and its impact on them; positively and negatively. The researcher has used The Survey Method, it was made on a sample which consisted of 202 students in the scholars' year (2008-2009). The sample was divided equally into males and females. However, after distributing the questionnaire; the sample became 192, the number of males was 95 and females were 97 . The study's results have shown that using internet is mostly used by the age group of 19-21 years, especially by juniors; the usage hours were (3-4). The study has also shown that the study sample mostly uses internet at home; especially at midnight. Using internet late might affect the student's health, academic achievement and daily activity. Moreover, the study has shown that males sample use websites of movies, songs, sport websites and prohibited websites. According to the study sample, using internet can lead to alienation from family, addiction, secrecy and anxiety. A large percentage of the study sample uses internet without the permission of parents. Therefore, there is a need for supervision by parents.

The study of Ravichandran (2009) aimed to examine the impact of mobiles Phones and their usage on teenagers from parents perspective in New Zealand. According to study results; on one hand, parents agreed on the importance of using mobile phones to communicate with their teenage children. On the other hand, parents have shown their concern from addiction on this technology and using internet through their mobiles. In addition, study results have shown that $\% 97$ of study sample which consisted of 111 , own mobile phones.

In 2008, Valkenburg \& Peter conducted a study about social interaction on internet and self-concept. The study sample's consisted of Dutch teenagers whose ages were between 10-17 years. Both of the researchers assumed that teenagers who suffer from loneliness and social anxiety mostly use internet to extinguish their identities more than others. The researchers asked a study question about variances between males and females. The study conducted a number of results, the most significant ones were feeling lonely and having anxiety from social interaction by the study sample was an indicator that teenagers express themselves to others on the internet. In addition, females have a higher level of loneliness and anxiety from social interaction. There were no variances in proving identities to others between males and females.

In 2006, Kraut applied a tracking study for a year, the study sample consisted of 93 families, in 8 blocks of a city and it consisted of 256 users in Pennsylvania. Each user was given an email with free internet subscription, a SIM card and a computer along with allowing researchers to observe and track participants in research using web for the study. Moreover, the study did not include children who are less than 10 years and interviews were made 
at home for the research. The study results have shown that adults make more social relationships than adolescents and the excessive use of internet leads to weak societal relationships in a family. In 2007, Dworak, Schierl, Bruns \& Strüder made a study about watching TV and computer, taking into consideration sleeping positions and times of studying. The study sample consisted of 200 children in the United States of America. The study concluded that being exposed to media is bad for a variety of behaviors.

Watching TV and playing computer games excessively can affect a number of psychological symptoms, especially emotions, behaviors and physical aches. In addition, attention problems like hyperactivity and family interaction. However, there is no sufficient knowledge about relationship between excessive TV watching and consumption of computer games. Polysomnography was used to study sleep quantity. Moreover, visual and verbal memory tests before being exposed to media and after the sleeping period were used to measure the impact on verbal and visual memory performance. Furthermore, results have shown that being exposed to TV and computer screens effect on sleeping and cognitive function of children.

\subsection{Study Problem and Questions}

Despite the fact that communication is the foundation of societal life; many social researchers have confirmed that addiction on modern technologies has a negative effect on youth and adolescents, as it affects indirectly the social life. Internet has become an alternative for socializing with friends and family, as the youth spend many hours on discovering a number of websites. Thus, the social values have changed; it increased the desire and tendency for loneliness and decreased social interaction and development. These technologies became a "best friend", it accompanied them daily and filled their free time and loneliness. The youth become slaves for this technology; it leads them to imaginary world and fake personalities, then they wake up feeling lonely.

Study problem and answers of its questions:

1. To which extent can technology affect adolescents?

2. Do the views of parents on using technologies change according to gender and qualification?

Secondly: Significance of study:

This study has a theoretical and practical significance as the following:

Theoretical significance:

The significance of study is stemmed from the fact that it seeks to identify the problem that each family could face through creating a frame for this issue which will help researches and scholars.

Practical significance:

The practical significance of this study is represented by providing researchers and specialists with the suitable psychometric scales for such researches. Moreover, it provides very important information because adolescents are private individuals. Decision makers, educationalists and parents can also benefit from the study's results.

\section{Method and Procedure}

The study has adopted the Descriptive analysis.

Study population: The study population consisted of 2300 parents of university students in the second semester of (2017-2018).

Study sample: The study consisted of 370 parents who were chosen using simple random sample.

\section{Study's Instrument:}

The study instrument was prepared based on the conceptual framework and previous studies like Boabdallah, 2016 and Rabee 2010 studies which consisted of four fields at the rate of eight items for: 'cognitive aspect, social aspect, emotional aspect, physical aspect and lastly the behavioral aspect. The answers choices were based on 5 Points Likert Scale: (totally agree, agree, neutral, disagree and totally disagree). The scale was given the following grades $(1,2,3$, and 4$)$ in a row.

Study Variables:

Dependent variables are gender and qualification (less than a bachelor, higher than a bachelor).The independent variables are the total degree of study instrument and the following fields: social interaction, health, physical, cognitive and behavioral.

Instrument Validity:

To confirm the validity of instrument, it was presented for a group of arbitrators in the Faculty of Education at 
the University of Jordan. Editing was made based on the provided notes.

Instrument Reliability:

To check the reliability of study instrument, a survey sampling was tested on a sample consisted of 35 parents. Then it was retested after two weeks. Table 1 shows Pearson Correlation Coefficient, Internal Consistency and Cronbach's alpha:

Table 1. The Dependent variables using retest and internal consistency

\begin{tabular}{cccc}
\hline Scale & Field & Reliability retest & Internal Consistency (Cronbach's alpha) \\
\hline 1 & Social & 0.83 & 0.84 \\
2 & Behavioral & 0.78 & 0.86 \\
3 & Cognitive & 0.79 & 0.84 \\
4 & Health/Physical & 0.80 & 0.90 \\
& Total degree & 0.87 & \\
\hline
\end{tabular}

According to Table 1 , the reliability retest values were between $(0.87)$ and $(0.78)$. While internal consistency values were between $(0.90)$ and $(0.84)$. Thus, the values serve the current study purpose.

\section{Research Limitations:}

The study results were limited by the used sample in addition to the instrument which was prepared for the purposes of the current study, the study results are controlled by the level of validity and reliability of this instrument.

\section{Statistical processing:}

The following procedures were used to answer the study questions:

Averages and Standard Deviations, MANOVA (multivariate analysis of variance),

T-test for dependent samples

\section{Results}

\subsection{Results of the first question}

To answer this question, table (2) shows the averages and standard deviations for the study instrument fields.

Table 2. Averages and Standard Deviations for the four fields in descending order

\begin{tabular}{ccccc}
\hline Field & Average & Standard deviation & Rank & Level \\
\hline Social & 3.91 & 0.74 & 1 & High \\
Behavioral & 3.80 & 0.53 & 2 & High \\
Cognitive & 3.72 & 0.84 & 3 & High \\
Health/Physical & 3.69 & 0.56 & 4 & High \\
Total degree & 3.78 & 0.67 & & High \\
\hline
\end{tabular}

Results of Table 2 show that the most affected field by using technology is the social field with an average of (3.91), then comes the behavioral field with an average of (3.80), the cognitive field with an average of (3.72), the health field with an average of (3.69) respectively. These results may due to the excessive use of technologies which alienates an individual from the surrounding environment and so they are not interested in exchanging visits with friends or even communicating with family members.

These results agreed with the results of Ravichandran' study (2009) which examined the impact of mobile phones on teenagers, parents' fears of bad usage of technology as a way for communication between parents and their children.

The following is a presentation for averages and Standard Deviations for each field.

Firstly: Social field 
Table 3. Averages and Standard Deviations for the items of social field in descending order

\begin{tabular}{|c|c|c|c|c|c|}
\hline Item & Items & Average & S.D & Rank & Level \\
\hline 5 & Computer should be placed in the living room in order to be supervised & 4.2 & 1.08 & 1 & High \\
\hline 4 & $\begin{array}{l}\text { Adolescents who publish personal pictures on social media will be exposed to } \\
\text { exploitation and extortion }\end{array}$ & 4 & 1.18 & 2 & High \\
\hline 7 & $\begin{array}{l}\text { I prefer that my adolescent son spend time with friends rather than sitting alone in } \\
\text { front of TV and computer }\end{array}$ & 3.99 & 1.36 & 3 & High \\
\hline 6 & $\begin{array}{l}\text { I believe that internet plays a big role in changing the societal values of an } \\
\text { adolescent and encourages individuality }\end{array}$ & 3.8 & 1.28 & 4 & High \\
\hline 2 & Immersion in technology can cause alienation and introversion to adolescents & 3.75 & 1.29 & 5 & High \\
\hline 1 & $\begin{array}{l}\text { Generally, internet and technology allowed adolescents to meet new friends which } \\
\text { might affect negatively on personality and behavior }\end{array}$ & 3.69 & 1.27 & 6 & High \\
\hline \multirow[t]{2}{*}{3} & Adolescents fights with siblings on possessing computer and TV might increase & 3.68 & 1.15 & 7 & High \\
\hline & Total degree & 3.91 & 0.92 & & High \\
\hline
\end{tabular}

According to Table 3 the average of social field was high (3.91) and the levels of all the items of this field were high averaging (3.68-4.20).

Secondly: Behavioral field

Table 4. Averages and Standard Deviations for the items of behavioral field in descending order

\begin{tabular}{|c|c|c|c|c|c|}
\hline Item & Items & Average & S.D & Rank & Level \\
\hline 9 & Parents should control the hours of using technology by an adolescent & 4.13 & 0.87 & 1 & High \\
\hline 7 & The privacy of an adolescent is mostly hidden using technology & 3.93 & 0.96 & 2 & High \\
\hline 6 & I agree on depriving adolescents from using mobile phones if used badly & 3.92 & 1.19 & 3 & High \\
\hline 3 & Adolescents spend long time on mobile phones & 3.87 & 1.12 & 4 & High \\
\hline 8 & $\begin{array}{l}\text { Adolescents try to apply the ideas and behaviors which they see through } \\
\text { technology }\end{array}$ & 3.77 & 1.01 & 5 & High \\
\hline 4 & Having cameras in cellphones can expose adolescents to problems & 3.74 & 1.28 & 6 & High \\
\hline 2 & Generally, internet is used in a bad way by adolescents & 3.72 & 1.11 & 7 & High \\
\hline 5 & Having cameras in computers can expose adolescents to abuse & 3.70 & 1.28 & 8 & High \\
\hline \multirow[t]{2}{*}{1} & Adolescents who play electronic games can have addiction & 3.68 & 1.18 & 9 & High \\
\hline & Total degree & 3.80 & 1.03 & & High \\
\hline
\end{tabular}

According to Table 4, the average of behavioral field was high (3.80). In addition, the levels of all the items of this field were high averaging (3.68-4.13).

Thirdly: Cognitive field

Table 5. Averages and Standard Deviations for the cognitive field in descending order

\begin{tabular}{clrrrr}
\hline Item & Items & Average & S.D & Rank & Level \\
\hline 6 & $\begin{array}{l}\text { It is necessary that parents raise adolescents' awareness of the dangers of using } \\
\text { technology. }\end{array}$ & 4.46 & 0.87 & 1 & High \\
3 & It is difficult for parents to accompany adolescents while using technology. & 3.88 & 1.19 & 3 & High \\
2 & Adolescents use internet to search and obtain useful information. & 3.8 & 1.26 & 4 & High \\
7 & $\begin{array}{l}\text { I prefer that my adolescent son spend time with friends instead of sitting alone in } \\
\text { front computer and TV. }\end{array}$ & 3.77 & 1.36 & 5 & High \\
8 & I think there is a knowledge gap between me and my son in how to use computer & 3.7 & 1.3 & 6 & High \\
\hline
\end{tabular}


and mobile.

1 I believe that the usage of internet by adolescents is a waste of time.

$3.69 \quad 1.47 \quad 7 \quad$ High

4 The existence of technology has a negative on the intellectual and cultural level. $\quad \begin{array}{lllll}3.67 & 1.32 & 8 & \text { High }\end{array}$

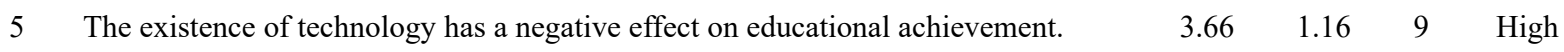

Total degree

$3.72 \quad 0.84 \quad$ High

According to Table 5, the average of the cognitive field was high (3.72), with a standard deviation of (0.84). The levels of all the items of this field were high averaging (3.68-4.13).

Fourthly: Health field

Table 6. Averages and Standard Deviations of field items in descending order

\begin{tabular}{clcccc}
\hline item & Items & Average & S.D & Rank & Level \\
\hline 2 & Adolescents depend on fast food as they are busy with technology. & 4.46 & 1.19 & 1 & High \\
1 & $\begin{array}{l}\text { I believe that sitting for a long time in front of computer causes health problems } \\
\text { for adolescents. }\end{array}$ & 4.07 & 1.03 & 2 & High \\
4 & $\begin{array}{l}\text { Some videos found on computers and mobile phones can psychological } \\
\text { problems for adolescents. }\end{array}$ & 3.50 & 0.95 & 3 & Average \\
3 & $\begin{array}{l}\text { Adolescents spend long time in front of TV watching useless entertainment } \\
\text { programs. }\end{array}$ & 3.30 & 1.15 & 4 & Average \\
& \multicolumn{1}{l}{ Total degree } & 3.69 & 0.89 & High
\end{tabular}

According to Table 6, the average of the health field was high (3.69). In addition, the levels of the items were high and average; averages were (3.30-4.46).

3.2 Results of the Second Question

Table 7 shows the Multivariate analysis of variance:

Table 7. Multivariate analysis of variance in averages of the degrees of impact for using technologies on adolescents based on gender and qualification

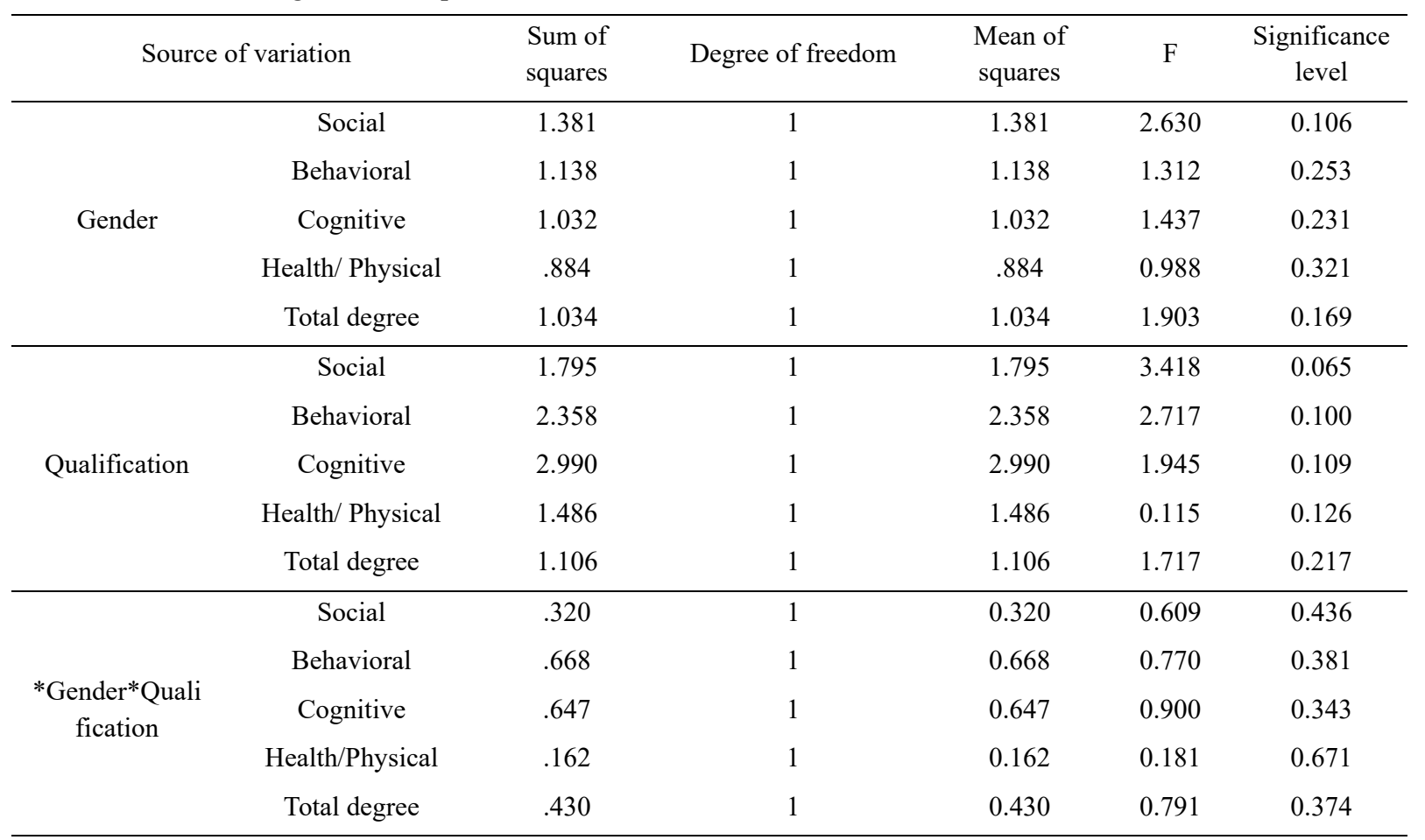




\begin{tabular}{ccccc}
\hline & Social & 192.205 & 366 & 0.525 \\
Error & Behavioral & 317.547 & 366 & 0.868 \\
& Cognitive & 262.950 & 366 & 0.718 \\
& Health/Physical & 327.416 & 366 & 0.895 \\
& Total degree & 198.817 & 366 & 0.543 \\
\hline \multirow{3}{*}{ Total } & Social & 5421.465 & 370 & \\
& Behavioral & 5176.347 & 370 & \\
& Cognitive & 4656.099 & 370 & \\
& Health/Physical & 4984.370 & 370 & \\
\hline
\end{tabular}

According to Table 7, the F value of gender variable was (1.903) and it is not statistically significant at (0.05) and therefore, there no statistic differences attributed to gender and parents' qualifications variables from their point of view about teengers' use of technology. Moreover, there is no statistical impact at (0.05) for the interaction between gender and qualification variables and this may due to the agreement on the results that technology usage and so, adolescents have the skills to deal with computer and internet connection and they are aware of negative and positive effects of using internet and technology in general. Items like (Adolescents use internet to search and get useful information) its average was (3.18) and (Internet affects negatively on the educational achievement of adolescents), its average was (2.05). These results can be attributed to parents' awareness of the risks of using technologies. These results agreed with the results of the study of Dworak, Schierl, Bruns \& Strüder (2007) which indicated that being exposed to media can affect a variety of behaviors badly. Watching TV and playing computer games excessively can cause several psychological symptoms and attention problems like hyperactivity and family interaction problems. Additionally, results have shown that being exposed to TVs, computers and screens can affect the cognitive performance of children.

\section{Recommendations}

In light of the study's results, researchers recommended the following:

- Supervise children while using technology.

- Limit the usage of these technologies as much as possible.

- Raise children's awareness of the dangers of using these technologies.

\section{References}

Al-Ghamedi, A. (2008). Adolescent frequently visiting internet café and its relationship with some psychological problems (Unpublished Master Thesis). Umm Al-Qura University, Saudi Arabia.

Al-kahki, A. (2009). Internet Psychological and social effects in UAE state (Unpublished Master Thesis). University of Sharjah, UAE.

Anderson, C. A. (2004). An update on the effects of playing violent video games. Journal of adolescence, 27(1), 113-122. https://doi.org/10.1016/j.adolescence.2003.10.009

Anderson, C. A., \& Bushman, B. J. (2001). Effects of violent video games on aggressive behavior, aggressive cognition, aggressive affect, physiological arousal, and prosocial behavior: A meta-analytic review of the scientific literature. Psychological Science, 12(5), 353-359. https://doi.org/10.1111/1467-9280.00366

Boabdlaha, S. (2016). Internet using and it is effect on adolescent student (Unpublished Master Thesis). Mohamed Qader University, Biskra, Algeria.

Burke, M., Kraut, R. E., \& Williams, D. (2010). Social Use of Computer-Mediated Communication by Adults on the Autism Spectrum. Proceedings of the international conference on computer-supported cooperative work, 425-434. https://doi.org/10.1145/1718918.1718991

Castell, M. (1996). Net and the self-working for critical theory of the information society. Critique of anthropology, 16(1). https://doi.org/10.1177/0308275X9601600103

Dietz, T. L. (1998). An examination of violence and gender role portrayals in video games: Implications for gender socialization and aggressive behavior. Sex roles, 38(5-6), 425-442. 
https://doi.org/10.1023/A:1018709905920

Durkin, K., \& Barber, B. (2002). Computer game play and positive adolescent development. JADP, 23, 273-392. https://doi.org/10.1016/S0193-3973(02)00124-7

Dworak, M., Schierl, T., Bruns, T., \& Strüder, H. K. (2007). Impact of singular excessive computer game and television exposure on sleep patterns and memory performance of school-aged children. Pediatrics, 120(5), 978-985. https://doi.org/10.1542/peds.2007-0476

Harvey, S. (2003). How Adolescents Use Technology for Health Information: Implications for Health Professionals from Focus Group Studies. Medical internet research. Retrieved April 29, 2012, from http://www.mawared.org

Ho, S., \& Lee, M. (2001). Computer usage and its relationship with adolescent lifestyle in Hong Kong. JAH, 29, 285-266. https://doi.org/10.1016/S1054-139X(01)00261-0

Kim, E. J., Namkoong, K., Ku, T., \& Kim, S. J. (2008). The relationship between online game addiction and aggression, self-control and narcissistic personality traits. European psychiatry, 23(3), 212-218. https://doi.org/10.1016/j.eurpsy.2007.10.010

Laeri, A. (2009). The effect of psychological and social problems accompanying computer user in internet café (Unpublished Master Thesis). Kuwait University, Kuwait.

Lee, D., \& LaRose, R. (2007). A socio-cognitive model of video game usage. Journal of Broadcasting \& Electronic Media, 51(4), 632-650. https://doi.org/10.1080/08838150701626511

Ohannessian, C. (2009). Does technology use moderate relationship between parental alcoholism and adolescent alcohol and cigarette use? University of Delaware, Newark, USA. https://doi.org/10.1016/j.addbeh.2009.01.001

Parker, J. D., Taylor, R. N., Eastabrook, J. M., Schell, S. L., \& Wood, L. M. (2008). Problem gambling in adolescence: Relationships with internet misuse, gaming abuse and emotional intelligence. Personality and Individual differences, 45(2), 174-180. https://doi.org/10.1016/j.paid.2008.03.018

Rabee, A. (2009). Imposing to Internet and its relationship with psychological and emotional effect oncountry youth (Unpublished Master Thesis). ManofiaUinversity, Egypt.

Ravichandran, S. (2009). Mobiles Phones and teenagers: Impact, Consequences and Concerns-Parent Perspective. UIT, 12(2), 12-36.

Rice, F. P., \& Dolgin, K. G. (2005). The adolescent: development relationships and culture. Boston, Pearson: Allyn and Bacon.

Santrock, J. W. (2003). Adolescence. New York, McGraw-Hill.

Smetana, J. (2006). Adolescent development in interpersonal and social contexts. Annual review of pysychology, 57, 255-284. https://doi.org/10.1146/annurev.psych.57.102904.190124

Stickle, F. E. (2007). Adolescent Psychology. USA, McGraw Hill.

Valkenburg, P. M., \& Peter, J. (2008). Adolescents' identity experiments on the Internet: Consequences for social competence and self-concept unity. Communication Research, 4(12), 23-50. https://doi.org/10.1177/0093650207313164

Wallenius, M. (2009). The association between information and communication technology (ICT) and peer and parent relations in early adolescence. Educational Research, 12(1), 23-60.

\section{Copyrights}

Copyright for this article is retained by the author(s), with first publication rights granted to the journal.

This is an open-access article distributed under the terms and conditions of the Creative Commons Attribution license (http://creativecommons.org/licenses/by/4.0/). 